\title{
A CONDUTA DO PROFISSIONAL MÉDICO MEDIANTE A VISÃO KANTIANA ${ }^{1}$
}

\section{ARTIGO ORIGINAL}

MARTINS, Valesca Cristina²

MARTINS, Valesca Cristina. A conduta do profissional médico mediante a visão kantiana. Revista Científica Multidisciplinar Núcleo do Conhecimento. Ano 04, Ed. 02, Vol. 01, pp. 20-35. Fevereiro de 2019. ISSN: 2448-0959

\section{RESUMO}

O presente artigo busca tratar de uma questão que está sendo discutida constantemente no âmbito jurídico, da responsabilidade civil do médico. Contudo, deve ser observado que a responsabilidade não está voltada apenas ao que foi imposto por uma constituição que vige em nosso país, mas também a um conjunto de normas dispostas pertencentes à área médica. Requisitos relevantes devem ser analisados, tais quais em primeira vista a deontologia médica, dificuldades encontradas e verificação do possível erro, uma vez que devem ser consideradas circunstâncias antecedentes necessárias que possam direcioná-lo a relativa conduta. Não obstante, o intuito do artigo é tentar verificar proposições que foram julgadas e

\footnotetext{
${ }^{1}$ Immanuel Kant, nascido em Königsberg, maior filósofo moderno com a obra "Crítica da Razão Pura", p.84, § 17. A proposição fundamental da unidade sintética da apercepção é o princípio supremo de todo uso do entendimento. 1ª edição - abril 1974.

Artigo apresentado na disciplina de elaboração de TCC, sob orientação da Professora - Sônia Helena Marra Diniz, como requisito parcial para obtenção do título de bacharel em Direito no $2^{\circ}$ semestre de 2015

${ }^{2}$ Bacharela do Curso de Direito Fead - Faculdade de Estudos Administrativos de Minas Gerais
} 
que venham a ser de relevância social na esfera médica, no posicionamento jurídico e pessoal do paciente, apresentando um processo de reconhecimento que consista em uma decisão justa e não errônea para as partes.

Palavras-Chave: Conduta médica, Erro médico, Deontologia, Questão jurídica, Paciente.

\section{CONSIDERAÇÕES INICIAIS}

O presente artigo tem o propósito de analisar no que versa a conduta do erro médico, uma vez que a responsabilidade civil médica compete em responder

por suas obrigações, enquanto que o Direito respalda em resguardar direitos e garantias referente à vida.

Se a medicina tem como finalidade evitar, curar ou atenuar certas enfermidades, ainda assim se tem o conhecimento de que a doença tem destinatário, porém em alguns casos, é apanhada de improviso por técnicas/manuseios empregados pelo profissional da área e/ou intercorrências advindas pelo estado imunológico do paciente.

O que se verifica é que na maioria das vezes, deve ser considerado em especial no caso da medicina, que mediante os fatos diversos e opostos, ocorridos em determinadas situações, o profissional habilitado pode vim a ser qualificado por sua conduta em decorrência por um erro de ofício. Relativo à síntese em questão, o intuito é verificar a relação de equidade sobre o comportamento ético e jurídico, uma vez que é estabelecido um conjunto de normas que devem ser cumpridas.

No primeiro momento será conceituada a questão da deontologia médica, sendo este um dos princípios fundamentais para a conduta do profissional. Uma vez que, tende aos Conselhos de Medicina a responsabilidade de disciplinar, fiscalizar e julgar os médicos, devolvendo-Ihes a confiança e o prestígio com que sempre foram distinguidos. 
Em segundo momento será analisado o Direito, de acordo com a Lei ‥ $-3.268 / 1957$ e pela Resolução do Conselho Federal de Medicina n. $1.931 / 2009$ referente legislação imposta e averiguar casos que incide sobre a conduta do profissional, uma vez que a sociedade é regida por normas.

Envolto este questionamento, foi utilizado como marco teórico os preceitos de Immanuel Kant, expostos no livro Crítica da Razão Pura, em que o homem, sendo dotado por uma racionalidade, o mesmo deve agir pelo dever que venha atender a coletividade e como segundo plano, foi utilizado a discussão de Hildegard Tagessel Giostri referenciando possíveis peculiaridades como culpa e obrigação advindos da conduta profissional médica em relevância à deontologia no ofício do profissional e a visão de Genival Veloso França, uma vez que a postura ética reporta a uma perfeição concebível no comportamento relativo à medicina. Tendo em vista que a dignidade da pessoa humana é um dos itens primordiais por não poder ser afiançado, e baseando na deontologia juntamente com o Código de Ética Médica, tende a pretensão de explanar um debate sobre o exercício médico e o Direito com seus ditames legais.

Desta forma, mesmo tendo ciência que a responsabilidade médica tem como resultado meio e não resultado fim é de suma relevância que normas devem ser cumpridas, mesmo sendo reconhecido pelos profissionais o cumprimento regido pelo Código de Ética Médica esbarrar com o imperativo prescrito na lei.

Haja vista que, Direito e Medicina são assuntos distintos defrontando com o mesmo objeto que é o bem jurídico da vida, mesmo se tendo o conhecimento que a medicina não se trata de uma ciência exata, conforme os dizeres de Genival Veloso de França (2011, p. 511): "O legislador, em colaboração com a Medicina, deverá buscar meios para fixar estruturas e estabelecer regras de Direito conforme a moral, os bons costumes e a ordem pública".

Por fim, o presente artigo desempenhará uma análise cuidadosa que tende a dar conhecimento sobre o assunto e tentar contribuir por meios de estudos realizados em livros, artigos, leis e casos registrados, considerações relevantes sobre a importância da ética médica e a importância do efeito da lei. 


\title{
DEONTOLOGIA, ÉTICA E MORAL SEGUNDO PRECEITOS BÁSICOS DETERMINANTES PARA VALORES DE JUÍZO BASEADO NO IMPERATIVO CATEGÓRICO DE IMMANUEL KANT
}

O termo deontologia foi criado em 1834 pelo inglês Jeremy Bentham, para exprimir sobre a ética profissional, sendo este um tratado referenciado aos deveres e à moral, de origem grega (déon), que significa dever, obrigação (SIGNIFICADOS, 2014). O que se observa no Código Deontológico, em seus Princípios Gerais, do artigo 1ํㅡ, baseiase que:

\begin{abstract}
A Deontologia Médica é o conjunto de regras de natureza ética, que com caráter de permanência e a necessária adequação histórica na sua formulação, o Médico deve observar e em que se deve inspirar no exercício da sua actividade (sic) profissional (DHNT, 2014).
\end{abstract}

Diante disso, pode-se dizer que a deontologia é parte da filosofia e esta está inserida na filosofia moral contemporânea, orientando os indivíduos em sua conduta, sendo conjunto de princípios e regras estabelecidos para regularização do exercício profissional.

No que tange a deontologia por seus preceitos de boa conduta, pode ser observado, que a mesma se torna peça importante, atribuindo uma estruturação de ordem, disposição esta imputada para um determinado fim incidindo na ética. Neste sentido, compete relacionar que a ética está vinculada ao caráter, ao modo de ser. Sendo o conjunto de regras de condutas, dependente de cada indivíduo, pois ter uma conduta ética é de consciência individual.

Contudo, a moral se refere a um conjunto de valores positivistas interligadas a regras, costumes e normas que regem a conduta dos homens em sociedade. Não obstante, a deontologia, a ética e a moral mesmo com seus significados diferentes, se configuram para um único fim, a atuação benévola sem ter que agir por obrigação e sim pelo dever de fazer o bem por boa vontade. 
Aqui, referindo a Immanuel Kant ${ }^{[3]}(1724$ - 1804), pode-se averiguar que os princípios morais resultam da razão prática e se aplica a todos os indivíduos em qualquer circunstância, sendo observado a ética do dever, estabelecendo assim, um caráter imutável e universal da moral.

Nas suas investigações, no livro da Crítica da Razão Prática, Kant negou a possibilidade de conhecermos a realidade que não passa pelo conhecimento sensível. Para ele, portanto, não é possível dizer nada sobre a alma humana e nem sobre Deus, pois os mesmos ultrapassam o nosso entendimento.

Kant, para responder esta questão fundamenta a moral na autonomia da razão humana. Para ele as normas morais devem surgir da razão humana. Sendo assim, ele recusou todas as éticas anteriores que tinha alicerce em normas e valores advindas de fora do sujeito, e imposta por outros meios que não sejam a razão. Kant entende que a razão é uma característica universal dos seres humanos, e isto que nos faz humanos. Para ele a razão deve indicar quais as normas e deveres a serem seguidos de forma universal.

Para Kant (1974, p. 221 - 232) tudo que estamos fazendo para as outras pessoas deve ser feito sem prejuízo para a humanidade. $\mathrm{E}$ isto deve nos guiar nos momentos de nossas decisões. Para ele uma conduta moral é a intenção de quem a praticou, e a melhor intenção é aquela que se volta para o cumprimento do dever. Aqui podemos falar do profissional médico: aquele que a conduta moral se torna bem para a humanidade; e aquele em que a conduta moral é feito com prejuízo à humanidade.

Seguindo a ética kantiana (KANT, 1974, p. 228 - 229) o profissional deve ser guiado nos momentos de decisão para o bem universal da humanidade. Dever e razão andam juntos na questão ética e moral kantiana. O que ele deixa bem claro, que não basta uma ação ser moralmente boa e que ela esteja de acordo com o dever, é preciso mais que isto: para Kant é necessário que ela seja feita por dever, isto é: o indivíduo tem que reconhecer naquele dever o princípio racional que o sustenta e isto é universal para todos. 
A intenção para Kant (1974, p. 228) é aceitação e o cumprimento do dever: isto se chama boa vontade. Então sendo assim, a boa vontade é que caracteriza a ação moralmente correta. Nisto podemos dizer que Kant responde sobre a liberdade do indivíduo como condição da lei moral, ou seja, aquela que pode ser realizada livre e autônoma.

Sem liberdade (KANT, 1974, p. 76 - 94) não há ação verdadeiramente moral. O grande eixo é conciliar ação e dever. Kant responde a isto propondo uma concepção de liberdade que coincide com o atendimento ao dever, pois liberdade seria uma possibilidade advinda da razão. Na crítica da razão pura ele trabalha esta instância como exigência da moralidade mostrando que a existência de Deus e a imortalidade da alma são necessidades morais do homem.

Quer-se dizer aqui, que a ética kantiana é uma ética formalista ela não fornece conteúdos morais, apenas o imperativo categórico "age de maneira que sua ação se torne uma ação universal", isto deve servir como orientação na escolha da concepção da natureza humana racional e livre (KANT, 1974, p.227 - 228, 231).

\section{MEDICINA E DIREITO - DA ÉTICA HIPOCRÁTICA E O IMPERATIVO CATEGÓRICO DE IMMANUEL KANT}

No tocante ao Corpus Hipocraticum (FRANÇA, 2011, p.512), regido à profissão médica, se interroga que mesmo com a velha e a nova ética médica, o juramento hipocrático tornou-peça fundamental no exercício da medicina, sendo este um ato ético inalienável, relativo à vida.

A complexidade da medicina com seus avanços, técnicas, pesquisas e meios utilizados não pode fazer com que o Direito se aparte, pois o sistema é regido por normas e, estas mesmas normas baseadas em princípios é que irá prevalecer para um bem estar social. 
Se o imperativo categórico está relacionado a um bem universal, compete aos profissionais, agir com o dever universal, "age de maneira que possas querer que o motivo que te levou a agir se torne uma lei universal".

A questão que se propõe Kant (ALMEIDA, 2009, p. 364): é ou não uma lei necessária para todos os seres racionais a de julgar sempre as suas ações por máximas tais que elas possam querer que devam seguir de leis universais? Esta pergunta feita por Kant está ligada ao conceito de vontade de um ser racional em geral está totalmente a priori. Para descobrir esta ligação de vontade e ação é preciso voltar-se na Metafísica dos Costumes, uma filosofia prática em que não temos que determinar os princípios do que acontece, mas sim a lei que deve acontecer, mesmo que nunca aconteça, quer dizer, leis objetivas prática. Então a necessidade da investigação sobre o sentimento do prazer e desprazer que resultam em desejos e tendências e destas com o curso da razão.

Trata-se, porém de uma lei objetiva prática, isto é, da relação de uma vontade consigo mesma enquanto esta vontade se determina só pela razão, porque se a razão por si só determina o procedimento, a vontade é concebida como a faculdade de agir em conformidade com a representação de certas leis.

Ainda assim, o juramento hipocrático:

Eu juro, por Apolo médico, por Esculápio, Hígia e Panacea, e tomo por testemunhas todos os deuses e todas as deusas, cumprir, segundo meu poder e minha razão, a promessa que se segue: Estimar, tanto quanto a meus pais, aquele que me ensinou esta arte; fazer vida comum e, se necessário for, com ele partilhar meus bens; ter seus filhos por meus próprios irmãos; ensinar-lhes esta arte, se eles tiverem necessidade de aprendê-la, sem remuneração e nem compromisso escrito; fazer participar dos preceitos, das lições e de todo o resto do ensino, meus filhos, os de meu mestre e os discípulos inscritos segundo os regulamentos da profissão, porém, só a estes. Aplicarei os regimes para o bem do doente segundo o meu poder e 
entendimento, nunca para causar dano ou mal a alguém. A ninguém darei por comprazer, nem remédio mortal nem um conselho que induza a perda. Do mesmo modo não darei a nenhuma mulher uma substãncia

(sic) abortiva. Conservarei imaculada minha vida e minha arte. Não praticarei a talha, mesmo sobre um calculoso confirmado; deixarei essa operação aos práticos que disso cuidam. Em toda casa, aí entrarei para o bem dos doentes, mantendo-me longe de todo o dano voluntário e de toda a sedução, sobretudo dos prazeres do amor, com as mulheres ou com os homens livres ou escravizados. Àquilo que no exercício ou fora do exercício da profissão e no convívio da sociedade, eu tiver visto ou ouvido, que não seja preciso divulgar, eu conservarei inteiramente secreto.

Se eu cumprir este juramento com fidelidade, que me seja dado gozar felizmente da vida e da minha profissão, honrado para sempre entre os homens; se eu dele me afastar ou infringir, o contrário aconteça (CREMESP, 2014).

e a máxima kantiana somado à deontologia no comportamento ético do médico hoje, nos remonta ao pensamento de como a prática do profissional com abordagens em questões multidisciplinares, relacionado e integrado a princípios inerentes ao comportamento agregado à valores sirvam na colaboração de uma atividade harmônica.

\section{O DIREITO ESPOSADO NA LEI № 3.268/1957 E RESOLUÇÃO DO CONSELHO FEDERAL DE MEDICINA № 1.931/2009}

Refletindo sobre a questão da conduta médica, a questão da responsabilidade pode ser interpretada pela Lei nº 3.268/1957 no que se refere à supervisão da conduta do profissional, conforme artigo $2^{\circ}$ :

Art. 2ํ: O conselho Federal e os Conselhos Regionais de Medicina são os órgãos supervisores da ética profissional em toda a República e ao 
mesmo tempo, julgadores e disciplinadores da classe médica, cabendoIhes zelar e trabalhar por todos os meios ao seu alcance, pelo perfeito desempenho ético da medicina e pelo prestígio e bom conceito da profissão e dos que a exerçam legalmente (BRASIL, 1957).

Com base nesta consideração, pode se vislumbrar que o Direito preceitua que o profissional exerça suas atividades segundo regras impostas à maneira prática e correta de seu ofício.

Fazendo uma ponte à lei citada acima, pode ser considerada que a responsabilidade médica embasada na deontologia conforme Antônio Moser (2006, p. 25) é: "A deontologia (do grego déon, dever), por sua vez, é uma norma jurídica que regula o ato profissional, estabelece as condutas que devem ser adotadas e pune aquelas reprováveis."

Sendo o Direito um fator social que estabelece regras para uma harmonização com a sociedade, normatizando e regularizando assuntos que estabeleçam uma comunicação conjunta no que venha configurar sua finalidade, pode ser observado que de acordo com José Renato Nalini (2005, p. 519): "O direito é um fato social. Cumpre sua função de conferir segurança à relações entre as pessoas. Sua finalidade é muito mais séria."

Com efeito, a Lei ํㅜ 3.268/1957 enfocando a Resolução do Conselho Federal de Medicina $n^{0}$ 1.931/2009, em seus dispostos artigos, em especial os artigo $3^{\circ}$ e artigo $50^{\circ}$, voltado à conduta médica, observa-se que:

Art. 3o: Deixar de assumir responsabilidade sobre procedimento médico que indicou ou do qual participou, mesmo quando vários médicos tenham assistido o paciente, e;

Art. 50ㅇ: Acobertar erro ou conduta antiética de médico (BRASIL, 1957).

No tocante a lei e à resolução, observar-se imposições previstas aos profissionais e refletindo na deontologia, a responsabilidade do profissional está voltada a uma 
obrigação de fazer, satisfazer e porque não reparar atos de seu exercício, quando este vem a causar dano ao paciente.

Sabe-se que alguns elementos são relevantes para o apontamento de um possível erro, sendo eles: médico, o ato do médico, ocorrência de culpa, o dano e ação ou omissão do profissional. Contudo, de acordo com Giostri (2011, p.43):

Funda-se na culpa, e a disposição tem por fim afastar a escusa que poderiam pretender invocar, de ser o dano um acidente no exercício de sua profissão; o Direito exige que esses profissionais exerçam sua arte segundo os preceitos que ela estabelece e com as cautelas e precauções necessárias ao resguardo da vida e da saúde dos clientes, bens inestimáveis, que se Ihes confiam, no pressuposto que deles zelem; e esse dever de possuir sua arte e aplicá-la, honesta e cuidadosamente, é tão imperioso que a lei repressiva the pune as infrações (GIOSTRI, apud BEVILÁQUIA, 2011).

Em consequência disso, o que leva a responsabilização médica, uma vez que o ato ilícito de conduta tende-se a incumbência de reparação ao dano?

No que pese à ilicitude do profissional, sabe-se que normas impostas devem ser cumpridas, e conforme Antônio Macena de Fiqueiredo (2006, p.13): "A profissão que se enobrece com a ação virtuosa de seus membros também pode comprometer a imagem de todos pela conduta não zelosa e inconveniente".

Contudo, pode ser observado que vários fatores estão propícios para a ocorrência do erro médico, mas no que tange a esta responsabilização, não se deve deixar de ser averiguado que por ser uma profissão que impõem status, a tradição ainda é sinônimo de conservadorismo na classe.

Refletindo sobre o possível erro médico, porém visando um acerto que venha a condizer para uma solução justa, no que versa a esta questão, pode ser aliado à teoria da disciplina deontológica juntamente com a prática em consonância à jurisprudência. Desta forma, a soma destes três fatores alicerça um caráter de solidariedade, mas, 
com a certeza de que determinados fatores sejam consideráveis aceitáveis na visão judiciária assegurando a sociedade.

Desse modo, saber distinguir o que cabe de direito as partes em conflito sem que ocorra uma preponderância ao erro, é inevitável que julgamentos venham de encontro com a realidade dos fatos. No que diz respeito ao bem jurídico da vida, o Direito sempre será exigido, contudo, deve ser observado quando este erro vem a ser uma falha de exercício ou uma intercorrência advinda do próprio sistema imunológico do paciente.

Baseando nestes pressupostos, pode ser observado no questionamento de Hildegard Taggesell Giostri (2011, p. 125):

Às vezes, é possível a ocorrência de um erro que, por ser de pequena monta ou por não deixar sequelas, passa despercebido ao cliente. Todavia, quando da ação ou da omissão do profissional advier um dano ao paciente - sendo que este dano poderia ter sido evitado - mas ocorreu por culpa comprovada (por imperícia, por imprudência ou por negligência) e havendo entre 0 dano e 0 ato médico 0 claro e indispensável nexo de causalidade, então deverá ele ser responsabilizado.

Contudo, é notório que a imposição do Código de Ética Médica juntamente com a Lei nº 3.268/1957 e a Resolução do Conselho Federal de Medicina nº 1.931/2009 verse na conduta médica, uma vez também que a ação judiciária não seja refém de si mesma, quanto a um julgamento errôneo de causa.

De maneira como se sabe, se o amparo do profissional está no Código de Ética Médica, o amparo referindo-se a justiça, está no Direito, mas sem que este lesione as partes envolvidas.

No que prevalece a esta sistematização de normas, é que as regras jurídicas devem ser obedecidas e principalmente analisadas, uma vez que referente conduta produzida ou não pelo profissional cai em distorção, pois deve ser observado não 
somente as normas gerais, sendo os princípios fundamentais, o direito médico, suas normas específicas e fundamentos que venham validar com as leis em disposição citadas acima.

No tocante, à proteção da vida, conforme José Geraldo de Freitas Drumond (2005, p.68):

Assim, quando as pessoas assumem a responsabilidade de executar funções relacionadas com as dimensões mais sagradas da existência, como a religião, a justiça e a saúde, e não atuam respeitando os valores morais inerentes à sua profissão ou função, toda a sociedade humana se torna diminuída em seus valores.

No entanto, para se determinar a responsabilidade médica, pode tomar como ponto de partida os princípios legais impostos pelo Juramento hipocrático, o pensamento kantiano e as leis impostas, quando o exercício médico não é cumprido corretamente de acordo com ditames legais.

Contudo, no que se refere a Lei 3.268/57 juntamente com a Resolução noำ1.931/09, portando para o viés kantiano, pode ser observado que a profissão médica deve assim se valer de um princípio prático, sendo este guiado pela conformidade da lei juntamente com a vontade regida no questionamento de Kant, uma vez que as ações realizadas pela obrigação do ofício médico deve ser realizadas de maneira tal que a não venha ferir a dignidade humana, uma vez que a vida é um bem inalienável.

\section{O NEXO CAUSAL COMO AÇÃO DE CAUSA DE AGIR MEDIANTE A LEI}

Observando que o nexo de causalidade quando um erro médico é previsto, neste sentido se incuti à responsabilidade, pois de acordo com Hildegard Taggesell Giostri, "nexo causal é a necessária relação que se estabelece entre a ação e sua causa de agir, de tal forma que o resultado final só pode ser imputado àquele ou àquilo que the deu causa" (GIOSTRI, 2011, p. 239).. Assim, ao inferir que o erro médico é 
consequência de um ato voltado a uma indiscrição de sua ligação relativamente à prática de seu exercício, pode ser notado que a ocorrência de previsibilidade cometida pelo profissional é aparente.

Contudo, quando este nexo causal é reportado ao erro de ofício praticado ao bem jurídico, em questão a vida, é observado e examinado neste sentido, que a interferência decorrente a esta ação proveio de um fato decorrido por ato displicente, não por intervenção do sistema imunológico do paciente em discussão.

Tendo em vista, que Direito para Kant é realmente o ser humano ser apto a ouvir sua razão, sendo esta voz da razão e da pura prática. Contudo a intenção moral no sujeito, de acordo com a ética kantiana refere-se antes de tudo a moralidade da ação, que é a moral do sujeito, tendo assim uma distância entre ética e a concepção médica.

Sobre este enfoque analisado podemos inferir o erro médico sobre vários aspectos, sendo estes: cansaço, negligência, falta de conhecimento, baixa resistência do paciente. Também é impossível para o médico atender em vários lugares, por escassez do pagamento relativo aos Planos de Saúde.

Contudo, para a ocorrência do erro médico o nexo de causalidade de acordo com Giostri:

Erro médico pode, então, ser entendido como uma falha no exercício da profissão, do que advém um mau resultado ou um resultado adverso, efetivando-se através da ação ou da omissão do profissional (GIOSTRI, 2011, p. 125).

Deve-se considerar também que o erro do profissional não está ligado por não ter tido um resultado esperado ao seu ofício e sim ser avaliado antes de tudo se houve intercorrência no procedimento realizado.

No que tange para a ocorrência do erro, pode assim ser também avaliado três fatores fundamentais, sendo eles a imperícia, imprudência e a negligência, pois por ser a vida 
um bem jurídico deve conter-se se a falha do profissional foi advinda de uma falha culposa ou dolosa.

Verifica-se, no entanto que para a ocorrência do erro do profissional a responsabilidade do mesmo precisa assim ser comprovada como refere-se nos dizeres de Giostri:

A ocorrência de um ato médico falho, comprovadamente culposo - não basta a mera presunção - e que vem gerar um dano por conta daquele mau resultado, materializado, seja como outro tipo de doença ou sequela -, em consequência da intervenção médica ou medicamentosa, pode dar nascimento a uma ação penal, podendo ser, de igual modo, apreciado pecuniariamente, dando condições que o mesmo possa ser ressarcido na área cível. De igual maneira, poderá dar azo a um processo éticoprofissional, junto à sua entidade de classe, conforme já mencionado (GIOSTRI, 2011, p. 42).

Visto isso, a responsabilidade tende a ser avaliada pelo nexo de sua causalidade e ser cumprida mediante as leis impostas, uma vez que é portado ao sujeito o bem de ser resguardado pela lei mediante um ordenamento jurídico imposto e pela ética profissional, uma vez que o profissional tem a necessidade de ater-se de sua conduta e não se beneficiar-se dela.

Outro fator relevante a este fato em questão sobre o nexo causal é que ao ser considerado que na causalidade a obrigação do profissional é avaliada, pois fatores relevantes podem ser atribuídos, de acordo com os dizeres de Luzia Chaves Vieira (2001, p. 84): "Assim, podemos dizer que não basta somente a culpa: o vínculo causal, que liga o dano à conduta do agente, deverá ser evidenciado".

Adequa dizer que se o ser humano é movido por uma razão, este deve agir conforme sua vontade sem que cause dano à outra pessoa, pois se é estabelecido um regimento de normas, as mesmas precisam ser respeitadas. 
Ser justo na visão kantiana é considerar que a mesma prevalece por três fatores essenciais, pois assim observa que a lei impõem obrigações e estas devem ser realizadas. Sendo aqui observados a incapacidade natural e culposa do profissional de acordo com Joaquim Carlos Salgado (2009, p. 75) na visão kantiana:

a) Justo é, em primeiro lugar, o que reconhece o único direito natural (inato), a liberdade, como igual para todos os seres racionais (o homem na humanidade);

b) Justo é, de outro lado, o que realiza as liberdades externas de todos os indivíduos, limitadas por um princípio de igualdade, isto é, segundo uma lei universal, no sentido de compatibilizá-las e tornar possível a sociedade organizada (o homem na sociedade civil);

c) Justa é, finalmente, a lei que realiza a liberdade no sentido de autonomia, ou seja, a lei que cada vez mais se aproxima do princípio de racionalidade, criando uma legislação jurídica universal, no sentido de ser expressão da vontade geral da qual cada um deve participar, como garantia da paz perpétua num reino dos fins (o homem na república e no contexto da sociedade das nações).

Contudo, observa-se que para a não ocorrência do erro do profissional o mesmo deve ater-se a sua vontade, seguida de uma racionalidade, condizendo a moralidade de sua ação, sendo assim avaliado principalmente a dignidade da pessoa humana.

No entanto, se o ser humano é precedido por uma responsabilidade, cabe ao mesmo agir por uma vontade, intermediado por uma moralidade, sendo esta ética e considerando as leis impostas por um ordenamento para assim ser avaliado sua ação mediante sua conduta, uma vez que o mesmo deve se alicerçado de cautela. 


\section{CONSIDERAÇÕES FINAIS}

No que tange aos escritos aqui referidos, podemos dizer que o exercício médico, a deontologia, a filosofia de Kant e as normas jurídicas estão todas interligadas ao valor inalienável da vida.

Todos os imperativos se exprimem pelo verbo dever e mostram a relação de uma lei objetiva, da razão para uma vontade que segundo sua constituição objetiva não é por ela determinada (uma obrigação), mas praticar ou deixar de praticar algo, deve-se ter a possibilidade da vontade como ação universal.

Bom é aquilo que por princípio preserva a vida por qualquer custo com leis objetivas do bem e pode ser determinada pela representação do bem, o querer deve coincidir com a lei. Sendo assim, as formas para exprimir as leis objetivas do querer em geral deve estar contidas na razão da vontade.

A humanidade sempre tentou preservar a dignidade da pessoa humana, que é um dos itens primordiais por não poder ser afiançado. A profissão médica que se enobrece deve ter como base esta preservação à vida.

Portanto, não seria errôneo o pensamento de até que momento a falta de conduta ética e princípios morais levaria a humanidade à descrença do profissional mediante atitudes e/ou praticadas produzidas pelo mesmo, em que esta se torna uma questão discutida no âmbito jurídico, imputando assim a negação do dever.

O objetivo para realizar a liberdade é o critério supremo e fundamento da ordem jurídica, por isto é necessária à conservação e desenvolvimento como forma de progresso moral. Nesta questão da liberdade fora da Constituição não há direito nenhum, isto significa que a lei é produzida para o bem estar do ser humano e esta deve estar contida no dever.

É mister a reforma do comportamento ético que pode tornar mais racional à ordem jurídica, citando aqui que por mais imperfeita ou irracional que possa ser, não pode 
ser destruído para constituir uma realidade perfeita, o texto aqui quer dizer que só a razão pode aperfeiçoar o comportamento ético e a ordem jurídica.

Nisto, podemos citar que os deveres e as normas a serem seguidos de uma forma universal está situada no dever moral ou imperativo categórico. Aqui entendemos que a razão é uma característica universal dos seres humanos, e isto nos distingue de outros seres da natureza. Só a razão deve indicar as normas a serem seguidos de uma forma universal.

Se o poder é conduzido a uma classe específica para análises faltosas do profissional, mas esta não é exercida por quem poderia exercê-la, observa-se que o poder da lei concentra-se em uma minoria que se diz detentor do poder, mediante a liberdade de quem tem o direito, mas não tem o comando de agir devidamente para fazer valer aquilo que the foi negado, à dignidade de ser assistido na sua enfermidade.

$E$, por conseguinte, a manifestação livre da pessoa que é lesada objetiva na Constituição legal, fundada no princípio de liberdade, que é a única perene.

É necessário perceber que a conduta médica muitas vezes não chega a um consenso juntamente com a deontologia e a filosofia. Parece por assim dizer, que o erro médico é abraçado por aqueles que têm a lei equivocada como mando para resguardar erros que deveriam ser evitados.

Basta dizer que só a liberdade com efeito na razão pode reformular a lei médica, não excluindo a sua estruturação, mas refazendo valer a liberdade e resguardando, curando e salvando a vida humana: inalienável e portanto ainda hoje um mistério.

Afinal, quem assume o erro médico?

\section{REFERÊNCIAS}

CREMESP. Missão, visão e valores. Disponível em < http://www.cremesp.org.br/?siteAcao=Historia\&esc=3 >. Acesso em: 20 de abril 2014). 
DRUMOND, José Geraldo de Freitas. O "ethos" médico: a velha e a nova moral médica. Montes Claros: Unimontes, 2005.

FIGUEIREDO, Antônio Macena de; FREIRE, Henrique; LANA, Roberto Lauro. Profissões da saúde: bases éticas e legais. Rio de Janeiro: Revinter Ltda, 2006.

FRANÇA, Genival Veloso de. Medicina legal. 9ª Edição. Rio de Janeiro: Guanabara Koogan, 2011.

GIOSTRI, Hildegard Taggesell. Erro médico: à luz da jurisprudência comentada. Curitiba: Juruá, 2011.

KANT, Immanuel. Crítica da razão pura e outros textos filosóficos. 1a Edição abril 1974. Editor: Victor Civita.

MACROTEMAS.

<http://www.dhnet.org.br/direitos/codetica/codetica_portugal/medcpt.html>. acesso em: 20 de abril 2014.

MARTINS, Ives Gandra da Silva, Direito Fundamental à vida. In: NALINI, José Renato. “A vida é*”. São Paulo: Quartier, 2005.

MOSER, Antônio; SOARES, André Marcelo M. Bioética: do consenso ao bom senso. Petrópolis: Vozes Ltda, 2006.

VIEIRA, Luzia Chaves. Responsabilidade civil médica e seguro. doutrina e jurisprudência. Belo Horizonte: Del Rey, 2001.

TRAVESSONI, Alexandre. Kant e o direito. In: ALMEIDA, Guido Antônio de. Kant e o princípio do direito. Belo Horizonte: Mandamentos, 2009.

SIGNIFICADOS.COM.BR.

<http://www.significados.com.br/deontologia/.> Acesso em: 20 abril 2014.

Enviado: Agosto, 2018 
Aprovado: Fevereiro, 2019 